\title{
Epistemologia de si próprio: Estamos em gaiolas?
}

\author{
Epistemología de sí mismo: ¿Estamos en jaulas? \\ Epistemology of oneself: Are we in cages?
}

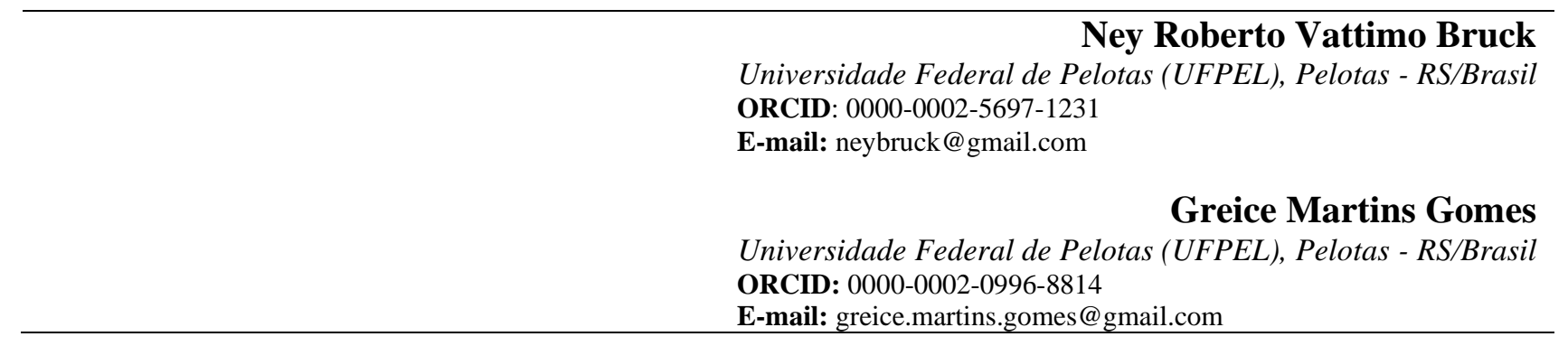

\begin{abstract}
Resumo
Este trabalho apresenta a concepção de epistemologia de si próprio, que é entendida como uma identificação de pressupostos científicos que mantemos internalizados e suas motivações. A tarefa da epistemologia de si próprio reside no desafio de objetivar a própria subjetividade, trazendo ao nível da consciência aquilo que está dentro de nós enquanto paradigma e preceito de verdade. Enquanto método, são apresentados e problematizados recursos pedagógicos utilizados em uma aula de psicologia, através de um movimento de ação-emoção-palavra com a consigna 'o que é preciso, em primeiro lugar, para sair da gaiola?’. Assim sendo, o método de análise utilizado é o de análise de conteúdo. Nesse sentido, o que é exposto por parte dos estudantes remete a uma disponibilidade e interesse de consciência crítica. Contudo, tal disposição, em uma sala de aula de hoje, mesmo remota, - que em muito pode nos lembrar a sala de aula de cem anos atrás - apresenta limites para se concretizar. Desse modo, aponta-se para a incerteza de que os métodos atuais utilizados pelas ciências da educação estariam respondendo aos desafios da sociedade.
\end{abstract}

Palavras-chaves: Epistemologia de si próprio; Aula de psicologia; Consciência crítica.

\section{Resumen}

Este trabajo presenta el concepto de epistemología de sí mismo, entendido como una identificación de los presupuestos científicos que mantenemos internalizados y sus motivaciones. La tarea de la epistemología de sí mismo es objetivar la propia subjetividad, llevar al nivel de conciencia lo que está dentro de nosotros como paradigma y precepto de la verdad. Como método, son presentados, y problematizados, recursos pedagógicos utilizados en una clase de psicología, a través de un movimiento de acción-emoción-palabra con el lema ¿qué es necesario, en primer lugar, para salir de la jaula?' El método de análisis es el del análisis de contenido. Lo que emerge, por parte de los estudiantes, se refiere a una disponibilidad e interés de consciencia crítica. Sin embargo, tal disposición, en una aula de hoy, incluso remota, que puede recordarnos mucho al aula de hace cien años, presenta límites para materializarse. Se apunta para la duda si los métodos actuales utilizados por las ciencias de la educación están respondiendo a los desafíos de la sociedad.
Palabras clave: Epistemología de sí mismo; Clase de psicología; Consciencia crítica.

\begin{abstract}
This paper presents the conception of epistemology of oneself, understood as an identification of scientific assumptions that we hold internalized and our motivations. The task of epistemology of oneself is to objectify the subjectivity of oneself, bring to the level of consciousness what is within us as a paradigm and precept of truth. The method presents pedagogical resources used in a psychology class, through an actionemotion-word movement with the slogan "what is needed, first of all, to think outside the box?" The method of analysis is that of content analysis. What emerges from the students refers to an availability and interest of critical awareness. However, such an arrangement, in a today's classroom - that reminds us a 100-year-old classroom - doesn't become an act. The question arises if the current methods used by the educational sciences are responding to the challenges of society.
\end{abstract}


Keywords: Epistemology of oneself; Psychology

class; Critical awareness.

Iniciaremos antecipando à nossa leitora, ao nosso leitor, que este texto se trata de um ensaio e que, como tal, se constitui "diferente do método tradicional da ciência, em que a forma é considerada mais importante que o conteúdo; o ensaio requer sujeitos, ensaísta e leitor capazes de avaliarem que a compreensão da realidade também ocorre de outras formas" (Meneghetti, 2011). Um ensaio aspira ser lido por sujeitos com espíritos desprendidos de preconceitos e, ao mesmo tempo, não dominados pelo formalismo da ciência. Motivo pelo qual nosso(a) leitor(a) não encontrará à disposição convencional um estudo que segue por uma divisão definida pelos métodos científicos tradicionais; no lugar de um objetivo geral, objetivos específicos, justificativa, fundamentação teórica e descrição sobre a metodologia aplicada, "no ensaio a orientação é dada não pela busca das respostas e afirmações verdadeiras, mas pelas perguntas que orientam os sujeitos para as reflexões mais profundas" (Meneghetti, 2011, p. 321, grifos nossos).

Essa é uma escolha que ficará evidente ao longo da leitura, bem como se mostrará coerente com a própria proposição do trabalho que foi desenvolvido e sobre o qual discutiremos neste material. Pode-se dizer que o que está escrito, aqui, é uma série de proposições para provocar o deslocamento de um lugar de conforto, de comodidade. Neste sentido, as ideias e práticas discutidas podem

\footnotetext{
1 O que norteia esta discussão refletirá, tanto sobre práticas anteriores, de mais de vinte anos de ensino universitário, experiências profissionais (explicitamente) singulares e uma formação acadêmica que se origina na filosofia e na psicologia e parte às posições (manifestadamente) heterogêneas, bem como sobre as vivências mais recentes adquiridas fora do cenário brasileiro, em um processo de aquisição de conhecimento que nunca é findado, nem se encerra em si mesmo. Heterogêneas aqui refere-se à Graduação em Filosofia, Mestrado em Educação e Doutorado em Psicologia como áreas de formação acadêmica, bem como experiências envolvendo Educação Popular, instituições psiquiátricas, clínica, trabalhos junto às
}

não apresentar encadeamentos entre os autores, pois concebemos mais como disparadoras, no sentido de capturas à potência de vida. É importante esclarecer também, desde já, que essa não é uma posição eclética, pois o ecletismo trata de juntar ideias que são extraídas de diferentes autores e correntes sem uma posição política clara. $\mathrm{O}$ que aparentemente é eclético se torna um avanço significativo na captação da realidade, visto que um esquema pode ser fácil de entender e isso não significa que irá condizer com a complexidade da realidade. Adiantamos ainda que, por vezes, podemos parecer exagerados, irônicos ou mesmo inconclusos, todavia, isso também é parte de uma proposta de trazer à tona o ar provocativo que se intenciona para instigar possíveis aprofundamentos de temas tratados neste ensaio ${ }^{1}$.

Nossos questionamentos nascem de uma inquietação ${ }^{2}$ que remete ao seguinte: se de um lado a educação tem a ver com construção do conhecimento, com a edificação de saberes, como algo que é fértil e criativo, da maneira que pode acontecer em sala de aula, de outro lado podemos nos questionar, assim como sugerido pela Análise Institucional (Ardoino, J. \& Lourau, 2003; Lourau, R., 1975; Barbier, 1985; Lobrot, 1977), como é possível, supondo em larga medida, observarmos um território acrítico nesta mesma sala de aula? Para tal provocação, tomaremos como pretexto de discussão uma aula ${ }^{3}$ ministrada em 2019, em

mulheres vítimas da violência doméstica e intervenções em alguns dos principais desastres brasileiros (Região Serrana do Rio de Janeiro, incêndio da Boate Kiss, entre outros).

${ }^{2}$ Este trabalho origina-se de um pós-doutoramento e mestrado sanduiche dos autores na Universidade de Coimbra, Portugal.

3 Parece-nos, ainda, interessante comentar sobre a trajetória da construção prévia da aula que discutiremos. Já em 2009, quando lecionávamos a disciplina de Psicossociologia em Emergências e Crises, em uma universidade brasileira, um dos temas do conteúdo programático chamava-se "epistemologia de si próprio" que, naquele momento, visava a promoção de 
um Curso de Graduação de Psicologia em uma universidade de Portugal. Por isso, aqui não há pretensão de pesquisa com todo o seu aparato metodológico, mas, sim, partimos de uma pergunta que mostra, também, a inquietude que motiva este ensaio: um estudo, ou uma pesquisa, serve para conhecer a realidade para melhor intervir nela ou trata-se de transformar a realidade para conhecê-la? (Kastrup, 2009).

Nosso esforço, portanto, baseia-se na noção de que "detectar padrões, temas e categorias é um processo criativo [...]. As pessoas que analisam dados qualitativos não têm testes estatísticos para dizer-lhes se uma observação é ou não significativa, elas devem basear-se na sua própria inteligência, experiência e julgamento" (Patton apud Lúdke \& André, 1996, p. 92, grifos nossos). Alertamos ainda que o que discutiremos não se trata evidentemente de um paralelismoocasional, quando nos referimos às experiências brasileiras (prévias) e às portuguesas (aqui discutidas), mas de formas comuns de manifestações, para as quais não intencionamos - nem acreditamos, que seja possível 'fechar' uma explicação, mas, sim, ajudar a traçar novas rotas, possibilitando visualizar perspectivas outras.

Antes de discorrermos sobre o que vem a ser uma epistemologia de si próprio, é importante esclarecer o que entendemos como epistemologia ${ }^{4}$. A complexidade envolvendo tal termo nos remete a alguns dos primeiros pensadores que direta, indiretamente e ainda sob as mais várias perspectivas (empiristas, positivistas ou realistas) se dedicaram a discutir o tema, tais como René Descartes, em seu O Discurso do Método (2001); David Hume, em

competências para lidar com situações dramáticas, estressoras, de tristeza e sofrimento, que caracterizam determinados incidentes críticos. A disciplina propunhase não só a melhoria da capacidade de enfrentar mudanças, redimensionar percepções e crenças, características estas indispensáveis para a prevenção de situações inesperadas e de risco, mas, também, a construção de elementos para o projeto de vida mais autônomo, reflexivo e emancipador. Foi a partir destas questões teórico-práticas que se elaborou a referida aula, ministrada fora do país, tendo como mote o que chamamos de "epistemologia de si próprio".
Investigação Acerca do Entendimento Humano (2004); Immanuel Kant, em Crítica da Razão Pura (2008); Thomas Kuhn, em A Estrutura das Revoluções Científicas (2007); Gaston Bachelard, na obra A Formação do Espírito Científico: contribuição para uma psicanálise do conhecimento (1997); seguidos de muitos outros estudiosos (Foucault, 1997; Mannheim, 1967; Merton, 1967, Luckmann, 1985; Bobbio, 1997; Morin, 1975, Blanché, 1983; Bunge, 1980; Japiassu, 1986; Bachelard, 1978; Morin, 1996; Santos, 2000).

Uma forma simplificada de pensarmos o que vem a ser a epistemologia pode ser feita através da seguinte perspectiva: iniciemos refletindo que uma ciência produz ciência, o que em outras palavras seria dizer: a psicologia produz psicologia, a sociologia produz sociologia, a biologia produz biologia e assim por diante. Agora, ainda que as ciências produzam alguns elementos para refletir sobre elas mesmas, necessitam também de outros campos do conhecimento nesta tarefa, e, em particular, da filosofia, que, nesse caso, se costuma chamar de epistemologia, ou reflexão epistemológica. Das muitas definições existentes sobre esse termo, o entendemos como sendo um conjunto de conhecimentos que tem por objeto o conhecimento científico e que busca compreender e questionar os seus condicionamentos, sejam técnicos, históricos, sociais, lógicos, matemáticos e linguísticos, cujo papel é o de identificar os obstáculos existentes no conhecimento comum, fixados no pensamento científico (Morin, 1975). De maneira geral, é preciso ter em mente que uma reflexão epistemológica prescinde de liberdade,

\footnotetext{
${ }^{4}$ A explicação sobre epistemologia será feita de forma breve e perfunctória, uma vez que o proposito deste material não é discutir o termo em si, haja visto a vasta produção neste sentido e todas as discussões quanto a isso, ensejadas ao longo dos tempos.
} 
de ousadia, de empenho na eliminação de crenças.

Essa é a ideia que nos levou à criação do que denominamos de epistemologia de si próprio, com inspiração nos pensamentos de Edgar Morin (1975) e de Paulo Freire (1993), autores que mais se aproximam desta perspectiva de 'ver-se é igual a ver melhor'. Isso significa questionar os pressupostos, nomeadamente os de base científica, que mantemos internalizados e suas motivações, ou seja, não é reflexo, mas, sim, uma reflexão sobre si mesmo. Entendemos uma epistemologia de si próprio como algo que remete a uma abordagem filosófica aplicada às concepções pessoais provenientes das ciências. Esse entendimento indica um diálogo interno que vise questionar filosoficamente nossa própria postura, uma vez que, para mudar o modo de agir é preciso modificar a própria imagem que temos de nós mesmos. Esclarecemos, para que não se confunda com o individualismo, tal como colocado pelos dispositivos neoliberais, que o sentido de epistemologia de si próprio não prescinde dos processos de alteridade, mas compreendemos dialeticamente como sendo integrante da relação educativa.

A tarefa de uma epistemologia de si próprio é 'objetivar a própria subjetividade', isto é, materializar, corporificar, tornar evidente, trazer ao nível da consciência e da percepção aquilo que está dentro de nós enquanto paradigma, preceito de verdade, ou convicção. A epistemologia de si próprio, enquanto metáfora, é como se fosse uma brecha que se origina da área de ambiguidades, de incertezas, ruídos e desordens: é a própria antiga questão do conhecimento e da ciência a relação do sujeito e do objeto. A brecha é esta dimensão, esta busca, que permanentemente fechamos pelas ideologias, pelas ciências e suas verdades, e que igualmente tentamos abrir com outras ideias (e ações) que, por sua vez, também mantem outros fechamentos. É como a relação ordem e desordem, aquilo que está em ordem desmontamos para mudanças (para sair do tédio) e vice-versa, diante de desordem procuramos colocar as coisas em ordem. Por exemplo, diante de uma situação que exige uma tomada de decisão, seja ela qual for, achamos uma resposta conveniente, mas, logo depois, talvez essa já não sirva mais. Essa mudança se deve, muitas vezes, não ao reflexo, mas à operação de reflexão sobre as próprias crenças, ao que nos remete às características da consciência crítica conforme apontado por Paulo Freire (1993). Deste modo, quando estas crenças se referem aos pressupostos das ciências que norteiam nossas visões de mundo ao emitir juízos e parâmetros para o projeto de vida e no cotidiano e quando nos debruçamos sobre tudo isso, dizemos que se trata de epistemologia de si próprio. Esta circularidade, esta indecisão, é a condição de possibilidade que simultaneamente limita e abre o prazer de saber.

Além disso, possivelmente trata-se de algo que importuna o campo dos valores, dos princípios e de como estamos e nos vemos no mundo. Esta é a essência da proposta da epistemologia de si próprio, já que serve como um elemento de desacomodação, de deslocamento, de desorganização e que se propõe justamente a abrir um espaço para um reorganizar. A epistemologia de si próprio origina-se da humanidade que existe em nós, uma vez que nosso interesse seja, em especial, estudar 'o humano'. Como ignorarmos o humano que habita dentro de nós?

A epistemologia de si próprio significa uma busca onto-antropológica em duvidar, em pôr em um momento de suspensão o que acreditamos ser realidade. Há de refletirmos, nesse sentido, que o fazer científico pode e deve ser um movimento de caráter emancipatório, justamente quando toma - o pensamento dado/naturalizado - como próprio objeto de reflexão. Para além do fazer acadêmico, a epistemologia de si próprio pode estar presente em nosso cotidiano, como reflexão perante a vida, sobre o ser e estar social, perguntando-se sobre os significados dos fenômenos e ressignificando as crenças que lhes dão sustentação. O que se propõe não se trata de um questionamento estéril, um questionar-se por questionar-se, mas um caminho de fuga de determinadas visões simplistas e reducionistas 
dos acontecimentos do estado inerte $\mathrm{e}$ paralisador de uma mesmice existencial, condicionados pelo hábito das "respostas prontas".

De tal maneira, a proposta sobre a qual nos debruçamos trata de um 'processo' que envolve um pensar (auto) reflexivo, crítico, indagador, um pensar ligado a uma noção de epistemologia de si próprio como condição de possibilidade, para que possamos romper com um sistema de ideias prévio. O exercício de saber remete ao exercício de abrir mão de certezas dogmáticas através de uma reformulação de nossos próprios fundamentos, ou como escreve Deleuze (2005, p. 24), "pensar é emitir singularidades, é lançar os dados" [...] "pensar é experimentar, é problematizar". Postas essas considerações, em busca de correlacionar tais proposições, vamos, a partir de agora, à aula ministrada durante o período pós-doutoral, que é o contexto da prática investigativa e dos processos grupais relatados aqui neste ensaio que, para fins de exposição neste material, será apresentada a partir de quatro momentos.

Tendo como foco temático a 'epistemologia de si próprio', o objetivo da aula foi de desenvolver as capacidades de aprendizagem autônoma e de análise crítica. $\mathrm{O}$ plano de aula envolveu um movimento de açãoemoção-palavra. As 'ações' remontam as atividades realizadas, uma comparação entre salas de aulas de hoje e do passado, sendo um exercício sobre equívocos da percepção (Momento três, descrito adiante) e uma discussão sobre a parábola do homem da gaiola. Já a 'emoção' está no processo de como essas atividades propiciam/geram emoções nos envolvidos; essas práticas foram elaboradas através de práticas discursivas e que envolvem, entre outras coisas, as 'palavras' ditas, as formas de expressão dos alunos.
Momento um: 'o(a) educador(a) parte do exemplo'. Um pouco antes do começo das atividades, todas as alunas e os alunos foram cumprimentados pessoalmente com um aperto de mão e com algumas palavras de boas-vindas. Foi um contato mais informal, em que o pressuposto norteador é de que o educador parte do exemplo. Além disto, partilhamos da noção de que a formalidade e a hierarquia entre estudantes e docente, de certa maneira, mais obstaculiza do que estimula um clima propício à aprendizagem.

Momento dois: 'discussões disparadoras'. O trabalho foi iniciado a partir de duas situações que pudessem servir como fio condutor quanto à compreensão sobre o que seria uma epistemologia de si próprio. Motivo pelo qual a escolha tangenciou elementos que desacomodassem o campo dos valores, dos princípios e de como estamos/entendemos estar no mundo. Uma projeção de PowerPoint sugeria alguns "disparadores" para tal discussão e nela se via duas imagens de salas de aula com cem anos de diferença, como representada na figura 1 .

Perguntas provocativas versavam sobre: como é possível praticamente o mesmo modelo de aula depois de todo este tempo? Por que tantas coisas mudaram e este espaço continua quase idêntico? Vocês estão confortáveis neste lugar com esta forma de ensinar e de aprender? Após essas perguntas, indicamos uma hipótese a ser considerada, que talvez não se trate de uma 'pedagogia de adultos', mas de uma pedagogia marcada por um viés infantilizado, feita e modelada nestes moldes e que, justamente, por isso - adultos no papel de alunos - tendem a se mostrar regredidos, ao agir de forma semelhante a crianças (retomaremos isso mais adiante). 


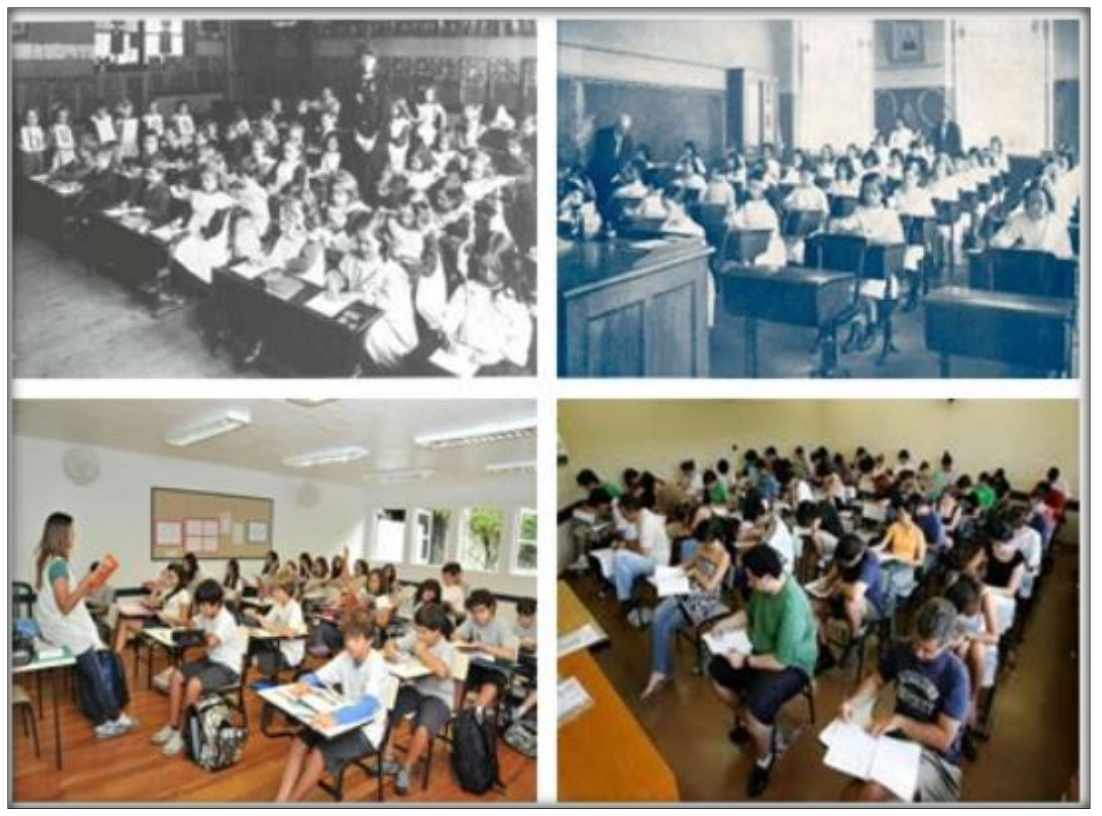

Figura 1. Salas de aula

Fonte: Desconhecida.

Momento três: 'Um exercício vivencial sobre os equívocos da percepção interna e externa' ${ }^{5}$. Para tanto, foi proposto que todas e todos iniciassem a atividade, fechando os olhos e que seguissem algumas orientações. Em busca de uma consciência sobre a percepção interna, as seguintes colocações foram feitas: "observe como sente o seu corpo, se há alguma parte que, de alguma forma, lhe é desconfortável, lhe incomoda. Agora, observe seus pensamentos, veja se eles lhe causam alguma inquietação, ou não, se interferem na sua concentração, ou não, se lhe importunam, ou entusiasmam, tendem a ser alegres, ou tristes, são encorajadores ou desestimulantes". Para colocar o foco da consciência sobre a percepção externa recomendamos: "sem se fixar em nada em especial, preste atenção nos ruídos a sua volta e em qual deles é o mais distante que consegue ouvir, sinta os aromas que estão a sua volta e que consegue identificar, preste atenção agora na temperatura, se está quente, se está frio, observe, sensorialmente, tudo mais o que consegue catar e que faz parte do seu ambiente externo. Esse exercício serviunos para iniciarmos a discussão quanto aos aspectos que envolvem duas possibilidades: ou

\footnotetext{
${ }^{5}$ Inspirado a partir da obra A razão cativa as ilusões da consciência: de Platão a Freud (ROUANET, 1990).
}

estamos no universo interno, ou estamos no universo externo.

Este é o elemento disparador para os argumentos que se focalizaram quanto às falsas certezas. É dito que não há uma certeza sobre as nossas percepções, talvez, que não saibamos, de forma unívoca, se as nossas percepções estão corretas. Muitas vezes, não sabemos exatamente o que se passa com o nosso corpo, pensamentos e sentimentos 'o que é mesmo aquele ruído, aquele aroma, esta sensação?'. A hipótese com a qual trabalhamos, e que foi desenvolvida ao longo do projeto pós-doutoral, é de que a nossa razão se encontra, reiteradamente, prisioneira entre os equívocos da percepção interna e os equívocos da percepção externa.

Momento final: 'o que é preciso então para sair desta gaiola na qual nos encontramos aprisionados?'. Para esta etapa, realizamos a leitura de "O homem que foi colocado numa gaiola" (May, 2012, p.121), que traz a seguinte parábola:

Certa noite, o soberano de um país estava de pé, à janela. Estava cansado da recepção diplomática a que acabara de comparecer e olhava pela janela, 
pensando sobre o mundo em geral e nada em particular. Seu olhar pousou sobre um homem que se encontrava na praça, lá embaixo, aparentemente um elemento da classe média. $\mathrm{O}$ rei começou a pensar como seria a vida desse homem. Imaginou-o chegando em casa, beijando distraidamente a mulher, fazendo sua refeição, indagando se tudo estava bem com as crianças, lendo o jornal, indo para a cama, dormindo e levantando-se para sair novamente para o trabalho no dia seguinte. E uma súbita curiosidade assaltou o rei, esquecendo-se por um momento de seu cansaço. Que aconteceria, se conservassem uma pessoa numa gaiola, como os animais do zoológico? No dia seguinte, o rei chamou um psicólogo, falou-lhe de sua ideia e convidou-o a observar a experiência. Em seguida, mandou trazer uma gaiola do zoológico e o homem de classe média foi nela colocado. A princípio, esse homem ficou apenas confuso, repetindo para o psicólogo, que o observava do lado de fora: "Preciso pegar o trem, preciso ir para o trabalho, veja que horas são, chegarei atrasado!" À tarde, começou a perceber o que estava acontecendo e protestou, veemente: "O rei não pode fazer isso comigo! É injusto, é contra a lei!" Falava com voz forte e os olhos faiscantes de raiva. Durante a semana, continuou a reclamar com veemência. Quando, diariamente, o rei passava pela gaiola, o homem protestava contra o monarca. Mas esse respondialhe: "Você está bem alimentado, tem boa cama, não precisa trabalhar. Estamos cuidando de você. Por que reclama?" Após alguns dias, as reclamações do homem começaram a diminuir e acabaram por cessar totalmente. Passaram-se mais algumas semanas e o prisioneiro começou a discutir com o psicólogo, se seria útil dar a alguém alimento e abrigo; afirmava que o homem tinha de viver seu destino de qualquer maneira e que era sensato aceitá-lo. Assim, quando um grupo de professores e alunos veio um dia observá-lo na gaiola, tratou-os cordialmente, explicando que escolhera aquela maneira de viver. Disse-lhes que havia grandes vantagens em estar protegido; que eles veriam com certeza quanto era sensata a sua maneira de agir, etc. "Que coisa estranha e patética", pensou o psicólogo. "Por que ele insiste tanto em que aprovem sua maneira de viver?" Nos dias seguintes, quando o rei passava pelo pátio, o homem inclinavase por detrás da gaiola, agradecendo-lhe o alimento e o abrigo. Mas quando o monarca não estava presente e o homem não percebia estar sendo observado pelo psicólogo, tornava-se impertinente e mal-humorado. Sua conversação passou a ter um único sentido: em vez de complicadas teorias filosóficas sobre as vantagens de ser bem tratado, limitavase a dizer frases simples como: "É o destino!" E repetia isso infinitamente. Ou então murmurava apenas: "É! É difícil dizer quando falou a última frase, mas o psicólogo percebeu que, um dia, o rosto do homem não tinha expressão alguma; o sorriso deixará de ser subserviente, tornando-se vazio, sem sentido. Em suas raras conversas, deixou de usar a palavra "eu". Aceitara a gaiola. Não sentia ira nem zanga; não raciocinava. Estava louco. Naquela noite, o psicólogo instalou-se em seu gabinete, procurando escrever o relatório final. Tinha dificuldade de encontrar termos corretos, pois sentia um grande vazio interior. Não podia afastar a ideia de que alguma coisa se perdera e fora roubado ao universo naquela experiência. E o que restava era o vazio" (May, 2012, p.121).

No que tange ao método e técnica, sobre o que vamos discutir a partir de agora, algumas considerações se fazem pertinentes. 
A técnica utilizada tanto para coleta quanto para análise de dados é a Análise de Conteúdo (AC). Optou-se por tomar como balizador as etapas propostas por Bardin (2004), que são organizadas em três fases: préanálise, exploração do material e, por fim, tratamento dos resultados, inferência e interpretação, que, à medida que interseccionadas, nos permitiram captar conteúdos manifestos e latentes e que podem ser ilustrados pelo gráfico em mandala a seguir (figura 2), que traz algumas das proposições que mais de evidenciaram na dinâmica efetuada em sala. Tal método se adequa ao objetivo de análise das respostas dadas pelos alunos e pelas alunas, pois como nos diz Bardin (2004, p. 26) "a análise de conteúdo, é um método muito empírico, dependente do tipo de 'fala' a que se dedica e do tipo de interpretação que se pretende como objetivo." No caso, optamos por não manter a atenção exclusiva aos conteúdos manifestos, mas sim estar atentos aos conteúdos latentes (Triviños, 1987; Bateson, 2000; Thompson, 1995; Denzin \& Lincoln, 2006).

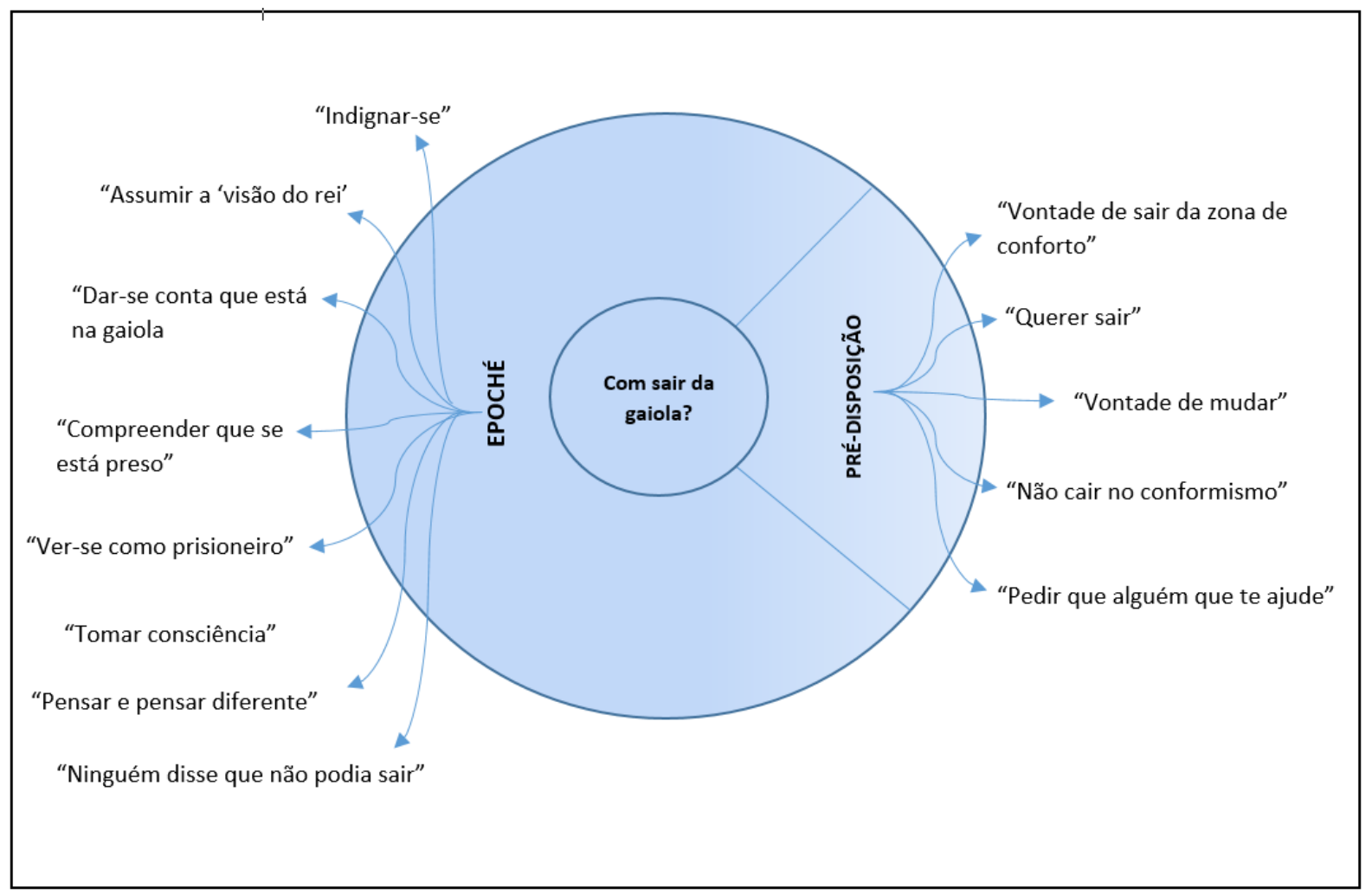

Figura 2. Como sair da gaiola?

Fonte: elaborado pelos autores (2020).

Os(as) alunos(as) posicionaram-se a partir de dois grandes temas que diziam respeito a uma predisposição para tomada de consciência, mas, em maior número, cerca de oitenta por cento da turma, reportou sobre formas de suspensão do juízo (epoché). De modo geral, o que se constatou foi que as diferentes respostas obtidas apontaram, entre outras coisas, para um pensar 'sobre' em vez de, 'a partir de', sendo esta a "chave" para sair da gaiola. Trata-se, neste sentido, de algo que caminha em direção à superação de percepções - muitas vezes, cronificadas e por isso mesmo aprisionadoras frente a uma mudança em busca de uma não (muitas vezes confortável) previsibilidade no roteiro da vida.

Enfim, qual é a primeira medida para sair da gaiola? A resposta parece simples: reconhecer que se está na gaiola. Para sair do lugar onde nos encontramos, precisamos 
primeiro reconhecer que estamos nele, entretanto, sair [da gaiola] não é tão fácil. As possíveis saídas passaram inevitavelmente sobre uma problematização quanto aos métodos atuais de ensino e aprendizagem e de uma (pré)disposição de contatar com a "suspensão do juízo". A suspensão do juízo (epoché) é um desfoque, é uma alteração da figura-fundo, abrindo o espaço-tempo para a ressignificação da relação sujeito-objeto para um desterritorialização. As respostas ditas pelos alunos e pelas alunas sobre "o que é preciso em primeiro lugar para sair da gaiola", reporta sobre a (pré)disposição de não conformidade e a compreensão de dar-se conta e, pode-se dizer, ter a coragem da consciência. O que emerge, por parte dos estudantes, remete a uma genuína e legítima disponibilidade e também interesse de consciência crítica, especialmente considerando a concepção de Paulo Freire (1993) ao expor as características da consciência crítica. Contudo, nossa posição é a de que tal disposição, em uma sala de aula de hoje - que em muito nos lembra a sala de aula de cem anos - não se torna ato. Seja qual for o significado atribuído a 'liberdade', tal como Rollo May (2012), podemos supor que a falta de liberdade gera ódio e ressentimento desde que a pessoa possa sentir e compreender esta opressão. Nas diferentes respostas dadas, percebe-se a inquietude que o tema provoca e, suspeito, tem a ver com a busca de sentido que damos ao mundo.

Uma hipótese possível versaria sobre a lentidão que envolve os processos institucionais e pelos medos da mudança, que pode significar perder o que já tem e adquirir o que não sabe. Para Bachelard (1994), a posição que deve gerir o pensamento científico contemporâneo, ao invés de alimentar a formação de obstáculos, precisaria operar dialeticamente tanto os valores experimentais, quanto os valores racionais, propondo mudanças diante de uma experiência nova. Tal disposição depende das circunstâncias ao invés de algo definitivo do espírito científico, ou seja, o julgamento do pensamento científico não advém do clássico racionalismo formal e universal, mas, sim, do particular aberto às novas possibilidades da experiência.

Em seu livro 'A Filosofia do Não', Bachelard (1974) propôs a rejeição de certezas e de saberes já estabelecidos, o que nos conduz a colocar em questão a própria constituição do pensamento, se trata, portanto, de uma ampliação do conhecimento, promovendo-se o rompimento das pré-noções do saber. Ainda assim, a instituição escolar parece viver uma contradição, pois, sendo seu objetivo o desenvolvimento do processo ensinoaprendizagem, o que se percebe, na prática, é que ela está permanente na luta contra esse objetivo. Uma luta constante entre seus objetivos e a fantasia de que estes - se alcançados - representariam sua destruição. Tal engendramento consegue alcançar a singular situação de, por um lado, não atingir plenamente seus objetivos e, por outro, que a estereotipia não se consiga estabelecer de forma a "tranquilizar". A luta é constante entre estes opostos e é gasta tanta energia em "manter", que o desgaste é visível nos sujeitos (alunos e professores) inseridos neste processo.

Certamente não é possível afirmar que/se, em algum momento, esta questão estará, verdadeiramente, desfeita, mas a intenção, aqui, é trazer qualidade à reflexão. E, isso requer uma alteração de concepções (doxas $e$ epistemes) na dimensão pedagógica do ensino, uma vez que, como escreve Boaventura de Sousa Santos (2018, p. 1), "os seres humanos, ao contrário dos pássaros, voam com raízes. Parte das raízes está nos conceitos que herdamos para analisar, ou avaliar o mundo em que vivemos". Na sala de aula, esse é o sentido de facilitar ao máximo as possibilidades de formular perguntas. Do ponto de vista epistemológico, tal atitude tem a ver ainda com a liberdade de formular questões - por quaisquer que sejam - algo como despressurizar as exigências de obediência que impedem a criação e, por isso, podem dificultar os processos de questionamento indispensáveis à produção cientifica.

Aprofundando a questão e a partir de um breve olhar sobre o pedagógico, vigente no 
ensino de adultos, observaremos que o que desponta se refere a um behaviorismo no modelo de aprendizagem, como, por exemplo, a visível aplicação de reforços positivos e negativos (punições), por meio dos instrumentos de controle nas avaliações e na frequência. Pongratz (2008, p. 46), referindo ao tema da "docilização dos corpos", de Michel Foucault, nos diz que "o que se disciplina, assim, é o próprio processo de aprendizagem, isto é, a absorção e a digestão de conhecimento didaticamente processado. $\mathrm{O}$ que também ocorre é a disciplina metódica dos sentidos, da postura corporal, do comportamento correto em sala de aula".

Neste sentido, parece não haver uma distinção entre pedagogia infantil e pedagogia de adultos, já que tais recursos são utilizados de maneira idêntica, sem levar em conta as etapas de desenvolvimento e de aprendizagem de alunos e alunas. Então, o que ocorre? O estudante, mesmo sendo adulto, cola em um papel que o desautoriza e imobiliza e, em última instância, o infantiliza, tornando-o regredido. Trata-se de uma violência na medida em que tal atitude desqualifica capacidades fundamentais do adulto, nomeadamente, a de autonomia. No dizer de Basaglia (1985, p. 36), "os graus de aplicação desta violência variam segundo as necessidades que aquele que detém o poder tem de oculta-la ou disfarça-la. Daí derivam diversas instituições que vão da família à escola, das prisões aos asilos de loucos". Ou ainda como coloca Pongratz (2008, p. 47),

[Uma] prática punitiva demonstra o quanto o efeito das sanções está junto de uma distribuição estruturada das sanções na instituição escolar. Nesse aparato de punição, o olhar fixo e punitivo do professor ocupa um lugar apenas casual, todavia com efeito mais intensivo do que as técnicas anteriores de punição, porque contém, de forma velada, a força sancionadora do sistema como um todo. (Pongratz, 2008, p. 47).
Ao passo que concordamos que "a pedagogia que anda por aí e que é a pedagogia da resposta. O educador entra na sala de aula trazendo uma valise de cheia de respostas cujas perguntas não lhe foram feitas. Ninguém lhe perguntou nada, e ele já vem trazendo as respostas" (Freire, 1997, p. 55). Assim, o que chamamos de uma epistemologia de si próprio aponta para a dúvida se os métodos atuais utilizados pelas ciências da educação estão respondendo aos desafios da sociedade. Defenderemos que, para sair desta situação de angústia da/na sala de aula, a superação do medo precisara passar, em primeiro lugar, por um empenho do(a) professor(a) nesta direção. E para tanto, o primeiro passo é que o docente tenha claro para si que, de certa forma, representa a instituição escolar e tudo que isso significa em termos de hierarquia e de produção de coerções, de obediência - e, sobretudo, de falta de liberdade - que é o motor da autonomia (Lobrot, 1977).

A postura alicerçadora de nosso argumento é de que não é mais possível se manter como espectador dos acontecimentos contraditórios, há que levar para a aula aquilo que é da vida em permanente movimento. Agindo assim, mesmo entre paredes, estaremos em mutação, desde que sejamos capazes de enfrentar os medos da mudança, sentindo, pensando e agindo sobre as implicações destas insatisfações no contexto escolar. Na atitude de 'compreender para agir' alertamos que é improdutivo tentar separar o dentro e o fora, pois, nenhum conflito não é só externo, já que diz respeito a um indivíduo complexo que tem dúvidas quanto a suas percepções internas e, da mesma forma, nenhum conflito é puramente interno, pois remete, em ato ou em potência, para conflitos sociais.

Toda a reflexão que se diga epistemológica prescinde da liberdade e da coragem para mudar crenças. É uma aprendizagem que necessita destas mesmas concepções enquanto pedagógico, ou seja, as alunas e os alunos precisam de um clima favorável que lhes permita ousar, criticar, contatar com as singularidades ao invés de reproduzir as hierarquias institucionais. Nesse 
sentido, parece claro que em um clima autoritário, como no método behaviorista skinneriano, a aquisição de competências de cunho epistemológico fica prejudicada. O que defendemos através de uma epistemologia de si próprio perpassa por uma dialética a qual se desenha através da razão e da experiência, pois rompe com certezas absolutas ao se propor a enfrentar o desconhecido.

É justamente a partir da complexidade de reconhecer a dificuldade de pensar, que se inicia o reconhecimento dos limites do conhecimento, é o lugar da dúvida não reducionista, que possibilita o crescimento do pensamento e do sonho, ou como diria Bachelard (1968), "nada é fixo para aquele que, alternadamente, pensa e sonha". Uma reflexão epistemológica prescinde de liberdade, de ousadia, de empenho na eliminação de crenças. Tais atitudes necessitam de um ambiente facilitador, cujas conexões, podemos dizer, são imperfeitas, na medida em que as relações de causa e efeito são muito diferentes das abordagens utilizadas nos cursos de exatas e ciências naturais. Queremos dizer que, aparentemente, o pedagógico utilizado em uma aula destes cursos é muito semelhante e sem distinções de uma aula em um curso de humanas.

Muitas vezes, o pedagógico utilizado nas aulas leva os alunos e alunas para um território de conforto acrítico, passivo às expectativas do professor, que por sua vez representa a instituição escolar. Partir destas premissas é indispensável para se dar conta de que a estratégia metodológica utilizada tem a ver com o conteúdo. Contra os reducionismos, existem brechas abertas dentro dos modelos, ou dos paradigmas, mapeamentos, concepções, ou seja, da visão de cada um, e que se projetam permitindo relacionar o que antes eram tabus e hoje estabelecem novas formulações teóricas. Nos processos de ensino-aprendizagem na sala de aula e na vida quotidiana, essa circularidade, essa indecisão, é a condição de possibilidade que simultaneamente limita e abre o prazer de saber e fazer, pois "é preciso abrir os sistemas de ensino a novas ideias. Em vez da homogeneidade e da rigidez, a diferença e a mudança" (Nóvoa, 2014, p. 184).

Tal como nos diz Bauman (2009), saibamos ou não, nossas vidas são obras de arte. Possivelmente pelo seu caráter de impermanência, podemos encontrar respostas nas práticas cotidianas da arte da vida, nas especificidades da produção científica (ou na epistemologia), escapando das concepções reducionistas para as relações estéticas, isto é, "fazer de sua existência uma obra de arte" (Bauman, 2009, p. 99). Ou será que ainda há alguma dúvida que existe arte nestas dimensões? A compreensão do inacabamento é o que permite se sensibilizar à mudança. Mudança no perguntar, mudança no olhar que, por sua vez, podem operar a transformação daquilo que é visto como sendo estático, sem movimento.

Perguntar-se pela história, pela gênese das ideias, pelo contexto que as gerou, desvendando, assim, sua trajetória e importância. Perguntar-se sobre os conceitos vigentes $\mathrm{e}$ as possibilidades de serem questionados quanto as suas verdades, valores e relevâncias, considerando as potencialidades de superação do instituído. Perguntar-se pela contribuição real ou potencial para repensar/refletir e transformar os modos de subjetivação dominantes. Sair dos papéis fixos, do script-de-vida, das convenções, das crenças. Sair das tiras autobiográficas, das modelagens e do behaviorismo que, por exemplo, predomina nos ambientes educativos. Isto é, perder as fidelidades para ver de outro jeito. Ao invés de coerções, o deixar fluir é a passagem à criatividade e às singularidades, elementos estes fundantes para pensar o que denominamos de epistemologia de si próprio.

Por fim, mesmo que a lógica de nossos argumentos tenha uma base empírica, como procuramos demonstrar, cabe ao(a) leitor(a) julgar por si o valor destas proposições. O entusiasmo sobre o que foi exposto, por ora não dissimulado, traduz a sinceridade de uma caminhada de coisas pensadas e escritas, no sentido de um convite para reflexão a todos(as) que pensam a educação, enquanto linhas 
autônomas, autogestivas e solidárias. Tais pressupostos talvez possam nos indicar caminhos, para investigações futuras, diante das dificuldades encontradas com microfones e câmeras desligadas no atual ensino remoto. Liberdade de escolha ou auto submissão à psicopolítica (Han, 2015)? Além disto, nossas reflexões sobre a relação entre forma e conteúdo, entre o pedagógico e o ensino de epistemologia em uma aula, remota, presencial ou híbrida, podem ser disparadores às ações, que se originam de interrogações, tais como: o que dá sentido ao mundo são as perguntas?

\section{Referências}

Ardoino, J., \& lourau, R. (2003). As Pedagogias Institucionais. São Carlos: RiMa.

Bachelard, G. (1974). A filosofia do não. São Paulo: Abril Cultural.

Bachelard, G. (1994). O direito de sonhar. São Paulo: DIFEL.

Bachelard, G. (1997). A formação do espírito científico: contribuição para uma psicanálise do conhecimento. Rio de Janeiro: Contraponto.

Barbier, R. (1985). A pesquisa-ação na instituição educativa. Rio de Janeiro: Zahar.

Bardin, L. (2004). Análise de Conteúdo. Lisboa: Edições 70.

Basaglia, F. (1985). As Instituições da Violência. Rio de Janeiro: Graal.

Bateson, G. (2000). Steps to a ecology of mind: collected in anthropology, psychiatry, evolution, and epistemology. Chicago: University of Chicago Press.

Bauman, Z. (2009). Arte da vida. Rio de janeiro: Jorge Zahar Ed.

Denzin, N. K., \& Lincoln, Y. S. (2006). $O$ planejamento da pesquisa qualitativa: teoria e abordagens. Porto Alegre: Bookman.

Descartes, R. (2001). Discurso do método. São Paulo: Martins Fontes.

Deleuze, G. (2005). Foucault. São Paulo: Brasiliense.

Freire, P. (1993). Educação e mudança. Rio de Janeiro: Paz e Terra.

Freire, P. (1997). Linguagem culta e linguagem popular. In P. Freire, \& P. Rivière, O processo educativo (pp. 55-57). Petrópolis, Vozes.

Han, B. (2015). Psicopolítica. Lisboa, Relógio D’Água Editores
Hume, D. (2004). Investigações sobre o entendimento humano e sobre os princípios da moral. São Paulo: Editora Unesp.

Kantt, I. (2008). Crítica da Razão Pura. Lisboa: Fundação Calouste Gulbenkian.

Kastrup, V. (2009). O funcionamento da atenção no trabalho do cartógrafo. In E. Passos, V. Kastrup, \& L. Escóssia (Orgs.), Pistas do método da cartografia: pesquisaintervenção e produção de subjetividade (v. 1, pp. 32-51). Porto Alegre: Sulina.

Kuhn, T. S. (2007). A estrutura das revoluções científicas. São Paulo: Perspectiva.

Lobrot, M. (1977). A favor ou contra a autoridade. Rio de Janeiro: Francisco Alves.

Lourau, R. A. (1975). Análise Institucional. Petrópolis: Vozes.

Lüdke, M., \& André, M. E. D. A. (1996). Pesquisa em Educação Abordagens Qualitativas. São Paulo, EPU.

May, R. (2012). O homem à procura de si mesmo. Petrópolis: Vozes, 2012.

Meneghetti, F. K. (2011). O que é um ensaioteórico?. Revista de Administração Contemporânea, 15(2), 320-332. doi: https://doi.org/10.1590/S141565552011000200010

Morin, E. (1975). O Enigma do Homem. Rio de Janeiro: Zahar.

Nóvoa, A. (2014). Educação 2021: para uma história do futuro. Revista Educação, Sociedade \& Culturas, (41), 171-185. Recuperado de https://www.fpce.up.pt/ciie/?q=publication/ revista-educa\%C3\% A7\% $3 \% \mathrm{~A} 30-$ sociedadeculturas/edition/educa\%C3\%A7\%C3\%A3o -sociedade-culturas-41 
Pongratz, L.A. (2008). Liberdade e disciplina: transformações na punição pedagógica. In A. Peters, (org.). Por que Foucault? Novas diretrizes para a pesquisa educacional (pp. 46-). Porto Alegre: Artmed.

Santos, B. de S. (2018). Os conceitos que nos faltam. Outras Palavras. Recuperado de https://outraspalavras.net/sem- categoria/boaventura-os-conceitos-que-nosfaltam/

Thompson, J. B. (1995). Ideologia e cultura moderna: teoria social crítica na era dos meios de comunicação de massa. Rio de Janeiro: Vozes.

Triviños, A. (1987). Introdução à pesquisa em ciências sociais: a pesquisa qualitativa em educação. São Paulo: Atlas.

\section{Dados sobre os autores:}

- Ney Roberto Vattimo Bruck: Professor no Centro de Artes da Universidade Federal de Pelotas (UFPEL), graduado em Filosofia (UFRGS), Mestre em Educação (UFRGS) e Doutor em Psicologia (PUCRS).

- Greice Martins Gomes: Mestre em Sociologia pela Universidade Federal de Pelotas (UFPEL) com mestrado Sanduíche pela Universidade de Coimbra (UC-PT). Atualmente é Doutoranda no programa de Pós-Graduação em Administração da Universidade Federal do Rio Grande do Sul (UFRGS).

\footnotetext{
Declaração de Direito Autoral

A submissão de originais para este periódico implica na transferência, pelos autores, dos direitos de publicação impressa e digital. Os direitos autorais para os artigos publicados são do autor, com direitos do periódico sobre a primeira publicação. Os autores somente poderão utilizar os mesmos resultados em outras publicações indicando claramente este periódico como o meio da publicação original. Em virtude de sermos um periódico de acesso aberto, permite-se o uso gratuito dos artigos em aplicações educacionais e científicas desde que citada a fonte conforme a licença CC-BY da Creative Commons.
} 